\title{
Draft genome sequence and characterization of commensal Escherichia coli strain BG1 isolated from bovine gastro- intestinal tract
}

\author{
Audrey Segura ${ }^{1 * \dagger} \mathbb{D}$, Pauline Auffret ${ }^{1 \dagger}$, Christophe Klopp $^{2}$, Yolande Bertin $^{1}$ and Evelyne Forano ${ }^{1}$
}

\begin{abstract}
Escherichia coli is the most abundant facultative anaerobic bacteria in the gastro-intestinal tract of mammals but can be responsible for intestinal infection due to acquisition of virulence factors. Genomes of pathogenic $E$. coli strains are widely described whereas those of bovine commensal E. coli strains are very scarce. Here, we report the genome sequence, annotation, and features of the commensal E. coli BG1 isolated from the gastro-intestinal tract of cattle. Whole genome sequencing analysis showed that BG1 has a chromosome of 4,782,107 bp coding for 4465 proteins and 97 RNAs. E. coli BG1 belonged to the serotype O159:H21, was classified in the phylogroup B1 and possessed the genetic information encoding "virulence factors" such as adherence systems, iron acquisition and flagella synthesis. A total of 12 adherence systems were detected reflecting the potential ability of BG1 to colonize different segments of the bovine gastrointestinal tract. E. coli BG1 is unable to assimilate ethanolamine that confers a nutritional advantage to some pathogenic E. coli in the bovine gastro-intestinal tract. Genome analysis revealed the presence of i) 34 amino acids change due to non-synonymous SNPs among the genes encoding ethanolamine transport and assimilation, and ii) an additional predicted alpha helix inserted in cobalamin adenosyltransferase, a key enzyme required for ethanolamine assimilation. These modifications could explain the incapacity of BG1 to use ethanolamine. The BG1 genome can now be used as a reference (control strain) for subsequent evolution and comparative studies.
\end{abstract}

Keywords: Escherichia coli, Commensal, Bovine, Gastro-intestinal tract, Whole genome sequencing, Virulence factors, Ethanolamine

\section{Introduction}

Escherichia coli is a common inhabitant of the gastrointestinal tract of humans and animals [1]. In particular, $E$. coli is typically the most common facultative anaerobe in the lower intestine of mammals and its presence in the environment is usually considered to reflect fecal contamination $[1,2]$. The E. coli population is multiclonal and fluctuates in its predominance depending on diet, exposure to antibiotics or interactions with the host endogenous microbiota [1].

\footnotetext{
* Correspondence: audrey.segura@inra.fr

${ }^{\dagger}$ Equal contributors

'Université Clermont Auvergne, INRA, MEDIS, F-63000 Clermont-Ferrand, France

Full list of author information is available at the end of the article
}

The intestinal microbiota predominantly comprises strict anaerobic bacteria, especially in the colon. E. coli exists in a symbiotic relationship with strict anaerobes: E. coli ferments monosaccharides generated by the degradation of polysaccharides by anaerobes $(E$. coli being unable to synthesize the necessary hydrolase enzymes) and in turn, E. coli is able to consume oxygen and therefore to favor the strict anaerobe multiplication by creating a more anaerobic environment $[2,3]$. Similarly, the host- $E$. coli relationship is mutualistic: the intestinal environment promotes efficient $E$. coli survival and multiplication and in turn, the $E$. coli population produces vitamins $\mathrm{K}$ and $\mathrm{B} 12$, which are required by mammalian hosts, and competitively excludes pathogens from the host intestinal tract [2]. E. coli strains are able to colonize various locations in the mammalian gastro- 
intestinal tract, but they are mainly found on the mucus layer used by E. coli as an essential nutritional source [4]. Successful colonization of the gastro-intestinal tract by $E$. coli depends upon several factors: competition for nutrients with the autochthonous microbiota, production of adhesins to bring the bacteria closer to the epithelia, penetration of the mucus layer, rapid growth and biofilm formation ability [1, 2, 4]. If E. coli growth does not exceed the turnover rate of the mucus layer, the bacterial cells are sloughed off into the intestine lumen and then eliminated in the feces [4]. Therefore, E. coli must display metabolic flexibility and grow in biofilm in order to succeed in this very competitive biotope [4].

Although considered as commensal in the mammalian gut, E. coli also causes a broad range of intestinal or extra-intestinal diseases due to the acquisition of mobile genetic elements encoding virulence factors. Among pathogenic E. coli, STEC is the major food-borne pathogen responsible for hemorrhagic colitis and hemolytic uremic syndrome [5]. In particular, a STEC strain subgroup EHEC belonging mostly to the serotype O157:H7 is responsible for serious public health concern and financial burden [5]. STEC strains are mainly transmitted to humans through contaminated meat or unpasteurized milk consumption [6]. It is of interest to note that healthy ruminants, mainly cattle, are the principal reservoir for $E$. coli O157:H7 strains, but cattle lack the Shiga-toxin vascular receptor, which explains why they are Shiga-toxin tolerant [6].

The cost of whole genome sequencing has decreased drastically and it is now possible to sequence a large number of isolates and use bioinformatic approaches to extract strain relatedness and gene carriage data. E. coli strains involved in human infections have been extensively studied and many whole genome sequences of $E$. coli associated with human illness are now available, allowing exploration of pathogenicity processes and identification of virulence factors. Due to cattle STEC dissemination, a significant number of whole genomes of $E$. coli $\mathrm{O} 157: \mathrm{H} 7$ strains isolated from bovine have also been sequenced. While previous genome sequencing efforts with commensal intestinal $E$. coli have focused on human strains [7-9], such data are scarce concerning commensal E. coli strains isolated from the bovine gastro-intestinal tract. It would be valuable to have recent and reliable genomic data on bovine commensal strains to be used as reference genomes.

In this study, we report the draft genome sequence and preliminary functional annotation of the commensal E. coli strain BG1 isolated from the digestive tract of a cow. The strain BG1 has been previously included in studies concerning the adaptation of pathogenic and commensal E. coli strains in the bovine gastro-intestinal tract $[10,11]$. This study aimed to characterize the genomic features of the BG1 strain in order to provide information for future genomic scale (whole genome) comparative analyses. The organism is not part of a larger genomic survey project.

\section{Organism information \\ Classification and features}

As described for the genus Escherichia, E. coli BG1 is a Gram-negative, rod-shaped bacterium belonging to the Enterobacteriaceae family (Table 1). E. coli is a facultative anaerobe that is motile by means of flagella (Fig. 1). E. coli strains are typically able to grow over a wide temperature range $\left(15-48{ }^{\circ} \mathrm{C}\right)$ with optimum growth

Table 1 Classification and general features of E. coli BG1 [58]

\begin{tabular}{|c|c|c|c|}
\hline MIGS ID & Property & Term & Evidence code $^{a}$ \\
\hline & Classification & Domain Bacteria & TAS [59] \\
\hline & & $\begin{array}{l}\text { Phylum } \\
\text { Proteobacteria }\end{array}$ & TAS [60] \\
\hline & & $\begin{array}{l}\text { Class } \\
\text { Gammaproteobacteria }\end{array}$ & $\operatorname{TAS}[61,62]$ \\
\hline & & $\begin{array}{l}\text { Order } \\
\text { "Enterobacteriales" }\end{array}$ & TAS [63] \\
\hline & & $\begin{array}{l}\text { Family } \\
\text { Enterobacteriaceae }\end{array}$ & TAS $[64,65]$ \\
\hline & & Genus Escherichia & TAS $[66,67]$ \\
\hline & & $\begin{array}{l}\text { Species Escherichia } \\
\text { coli }\end{array}$ & TAS $[66,67]$ \\
\hline & Gram stain & Negative & IDA, TAS [1] \\
\hline & Cell shape & Rod & IDA, TAS [1] \\
\hline & Motility & Motile & TAS [1] \\
\hline & Sporulation & None & TAS [1] \\
\hline & Temperature range & $\approx 15-48{ }^{\circ} \mathrm{C}$ & TAS [1] \\
\hline & Optimum temperature & $37-42^{\circ} \mathrm{C}$ & TAS [1] \\
\hline & pH range; Optimum & $5.5-8.0 ; 7$ & TAS [1] \\
\hline & Carbon source & $\begin{array}{l}\text { Carbohydrates, } \\
\text { amino acids }\end{array}$ & IDA, TAS [1] \\
\hline MIGS-6 & Habitat & $\begin{array}{l}\text { Bovine digestive } \\
\text { tract }\end{array}$ & IDA \\
\hline MIGS-6.3 & Salinity & Not reported & \\
\hline MIGS-22 & Oxygen requirement & Facultative anaerobe & TAS [1] \\
\hline MIGS-15 & Biotic relationship & Commensalism & IDA \\
\hline MIGS-14 & Pathogenicity & Non-pathogenic & \\
\hline MIGS-4 & Geographic location & France & \\
\hline MIGS-5 & Sample collection & January 14, 2009 & \\
\hline MIGS-4.1 & Latitude & Not reported & \\
\hline MIGS-4.2 & Longitude & Not reported & \\
\hline MIGS-4.4 & Altitude & Not reported & \\
\hline
\end{tabular}

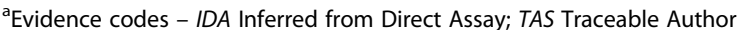
Statement (i.e., a direct report exists in the literature); NAS Non-traceable Author Statement (i.e., not directly observed for the living, isolated sample, but based on a generally accepted property for the species, or anecdotal evidence). These evidence codes are from the Gene Ontology project [68] 


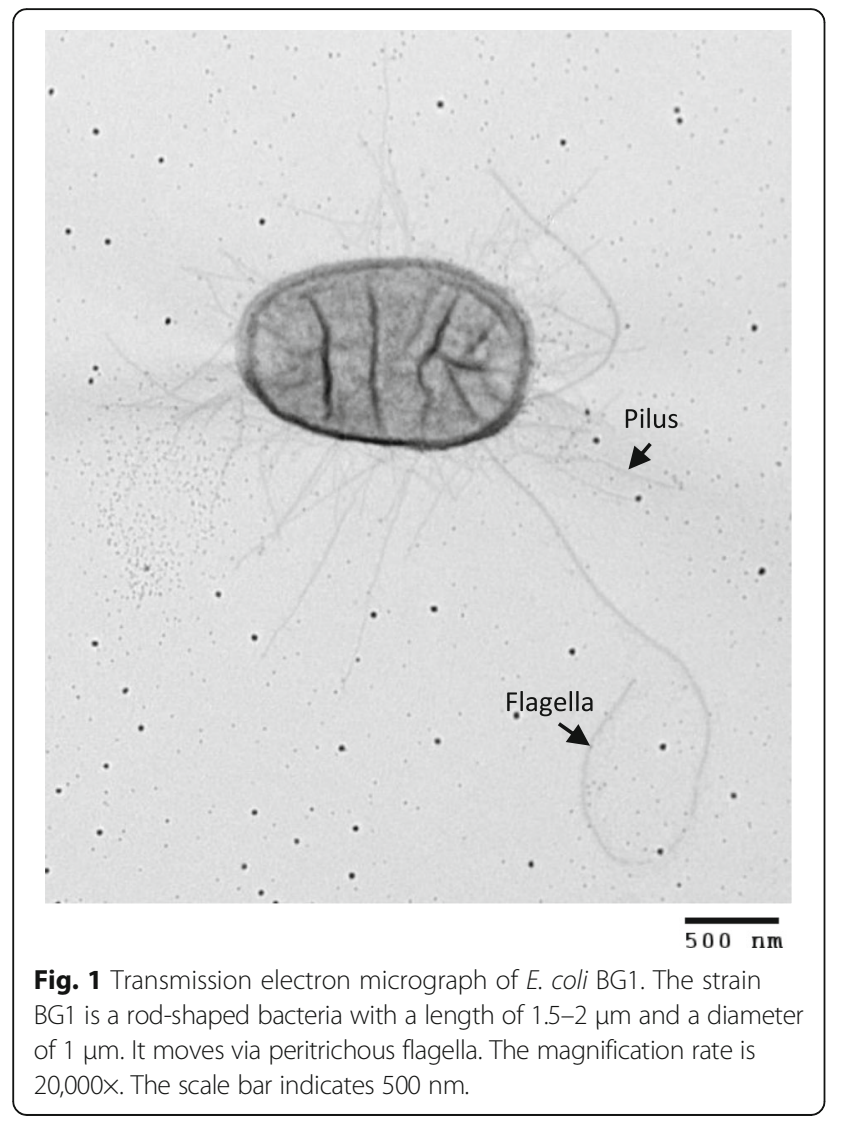

from 37 to $42{ }^{\circ} \mathrm{C}$ and within a $\mathrm{pH}$ range of 5.5-8.0 (the best growth occurs at $\mathrm{pH} 7$ ) [1] (Table 1). Like typical members of the E. coli species, the commensal strain BG1 utilizes D-glucose, D-mannitol, L-rhamnose, D-saccharose, D-melibiose and L-arabinose. Unlike most pathogenic O157:H7 EHEC strains, the strain BG1 is able to use sorbitol as a carbon source. In addition, E. coli BG1 is positive for arginine dihydrolase, ornithine decarboxylase, $\beta$-galactosidase and indole production.

In silico serotyping using SerotypeFinder (version 1.1) [12] revealed that E. coli BG1 belongs to the serotype O159:H21. The whole genome of $E$. coli BG1 lacked all the genes encoding antimicrobial resistance screened using ResFinder (version 2.1) [13]. E. coli strains can be divided into different phylogroups (A, B1, B2, D and E) commonly used to investigate the evolution and diversity of E. coli strains [14]. Phylogrouping was performed in silico using the quadruplex method described by Clermont et al. [14] and the primersearch program from the EMBOSS open software suite [15]. E. coli BG1 belongs to the phylogroup B1, which is commonly distributed among both bovine commensal and human pathogenic E. coli strains [16, 17].

A whole genome phylogenetic analysis based on single nucleotide polymorphism (SNP) differences in E. coli
BG1, bovine and human commensal E. coli strains, bovine pathogenic E. coli strains and bovine O157:H7 STEC strains (Additional file 1: Table S1) was conducted using CSI Phylogeny (version 1.4) [18]. Published E. coli genomes representing different $E$. coli pathotypes were selected for genomic comparison (Additional file 1: Table S1). In addition, two reference $E$. coli strains, one of which is the E. coli type strain $\left(\mathrm{NCTC} 9001^{\mathrm{T}}\right)$, were also included in this study. As shown in Fig. 2, the bacterial strains were clustered according to the phylogroup classification: BG1 was clustered with commensal and pathogenic E. coli strains belonging to phylogroup B1 (EHEC, STEC, ETEC, EAEC, APEC and E. coli responsible for postpartum metritis in dairy cows). The closest relative strains to BG1 were E. coli $\mathrm{K} 71$ isolated from the environment of a cow shed and $E$. coli W26 isolated from bovine feces, both of which belong to the phylogroup B1 (Fig. 2). In contrast, BG1 was more distantly clustered to pathogenic bovine and human E. coli strains (Fig. 2). However, E. coli KCJ852 (phylogroup B1), which is responsible for metritis, was more closely clustered to BG1 than the P4 and VL2732 strains associated with bovine mastitis (phylogroup A) (Fig. 2). It is of interest to note that i) the bovine $E$. coli strains of commensal origin (BG1, K71 and W26) were distantly related to bovine STEC O157:H7 strains (phylogroup E) and ii) the SNP-based phylogeny analysis failed to cluster the commensal $E$. coli strains according to their human or animal origin.

\section{Genome sequencing information}

\section{Genome project history}

Bovine commensal E. coli strains are poorly documented. Therefore, the E. coli BG1 strain was selected for genome sequencing to provide valuable genetic information for future genomic scale (whole genome) comparative analysis. E. coli BG1 has been used as a reference strain in studies related to carbon and nitrogen nutrition of $E$. coli strains in the bovine gastro-intestinal tract $[10,11]$. The strain BG1 was isolated from the small intestine content of a cow at the slaughterhouse in January 2009. The animal was raised and slaughtered in accordance with the guidelines of the local ethics committee and current INRA (National Institute for Agricultural Research) ethical guidelines for animal welfare (Slaughterhouse Permit number: 63,345,001). The bovine intestinal samples were collected after the slaughter of animals required for experiments specifically approved by the "Comité d'éthique en matière d'expérimentation animale en Auvergne" (Permit number: CE22-08) in the experimental slaughterhouse of the "Herbipole", INRA Saint-GenèsChampanelle, France. The Whole Genome Shotgun project was deposited at DDBJ/ENA/GenBank under the accession MOAH00000000 (Oct 31, 2016). A summary of the sequencing project information is provided in Table 2. 


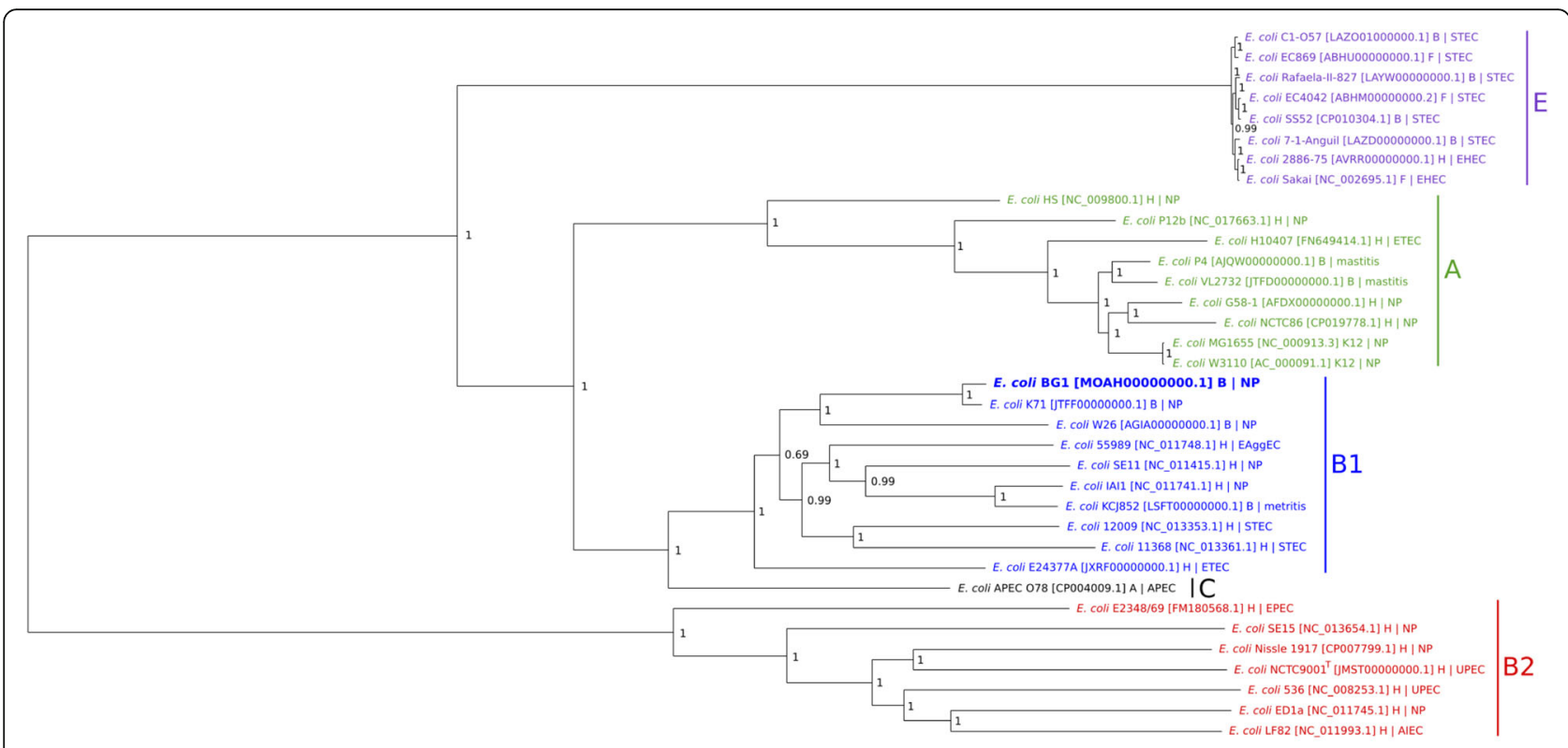

Fig. 2 Phylogenetic tree highlighting the position of E. coli BG1 relative to other E. coli strains. The whole genome SNP based phylogeny was established with CSI phylogeny 1.4 [28] using the genome of K71 as a reference and standard input parameters. The tree was midpoint rooted and plotted using Seaview (version 4.6.1) [56]. Each strain is identified as H (Human), B (Bovine), A (Avian), F (Food) or K12 (Laboratory strain), and its clinical or non-pathogenic (NP) characteristic is specified.

\section{Growth conditions and genomic DNA preparation}

E. coli BG1 was inoculated in Luria-Bertani broth from a single colony and incubated at $37{ }^{\circ} \mathrm{C}$ with shaking (200 rpm) to early stationary phase. The bacterial suspension was then centrifuged (10,000 $g$ for $15 \mathrm{~min}$ ) and the total DNA was extracted from the bacterial pellet using the DNeasy Blood and Tissue Kit following the manufacturer's recommendations (Qiagen). DNA was

Table 2 Genome sequencing project information for E. coli BG1

\begin{tabular}{lll}
\hline MIGS ID & Property & Term \\
\hline MIGS 31 & Finishing quality & High quality draft \\
MIGS-28 & Libraries used & Paired ends library \\
MIGS 29 & Sequencing platforms & Illumina MiSeq \\
MIGS 31.2 & Fold coverage & 127× \\
MIGS 30 & Assemblers & SPAdes version 3.1.1 \\
MIGS 32 & Gene calling method & PROKKA version 1.10 \\
& Locus Tag & BLX34 \\
& Genbank ID & MOAH00000000 \\
& GenBank Date of Release & 2017-02-24 \\
& GOLD ID & \\
& BIOPROJECT & PRJNA351833 \\
& Source Material Identifier & BG1 \\
MIGS 13 & Project relevance & Commensal E. coli \\
& & (control strain) \\
\hline
\end{tabular}

quantified using a Nanodrop spectrophotometer and DNA integrity was electrophoretically verified by ethidium bromide staining.

\section{Genome sequencing and assembly}

Whole genome sequencing was performed at the GeTPlaGe core facility (INRA Toulouse, France). DNA-seq libraries were prepared according to Illumina's protocols using the Illumina TruSeq Nano DNA LT Library Prep Kit. Briefly, DNA was fragmented by sonication using a Covaris M220 and adapters were ligated to be sequenced. Eight cycles of PCR were applied to amplify libraries. Library quality was assessed using the Agilent Bioanalyzer and libraries were quantified by qPCR using the Kapa Library Quantification Kit. DNA-seq experiments were performed on an Illumina MiSeq using a pairedend read length of $2 \times 250 \mathrm{bp}$ with the Illumina MiSeq Reagent Kits v2. The raw reads were stored in ng6 [19] and quality was checked using fastqc [20]. They were assembled with SPAdes (version 3.1.1) [21] using standard parameters.

\section{Genome annotation}

The assembled contigs were annotated with Prokka (version 1.10) [22] using standard parameters. Predicted genes were also assigned to functional categories of Clusters of Orthologous Groups (COGs) of proteins 
using blastp against the NCBI COG 2014 database [23]. Additional gene features were predicted using TMHMM Server 2.0 [24], SignalP Server (version 4.1) [25], CRISPRfinder (last update 2016-09-01) [26] and ISsaga (version 2.0) [27]. PHASTER [28] was then used to identify prophage regions in the BG1 genome. A prophage region was considered to be intact if the associated completeness score was above 90, questionable if the score was between 70 and 90 and incomplete if the score was less than 70 [28].

\section{Genome properties}

The genome of $E$. coli BG1 consists of 4,782,107 bp with no discernible plasmid (no match retrieved with PlasmidFinder version 1.3 [29]), and a $G+C$ content of $50.7 \%$. The genome has been assembled into 84 contigs. Of the 4562 predicted genes, 4465 coded for protein and 97 were RNArelated (including eight $5 \mathrm{~S}$ rRNA genes, suggesting the presence of 8 rRNA operons, and 86 tRNA genes). In addition, 22 pseudo genes were identified. Among the 4465 protein coding genes, 3831 (85.8\%) had an assigned function while the 634 remaining genes $(14.2 \%)$ encoded proteins annotated as hypothetical or unknown. In addition, the BG1 genome contained 38 predicted insertion sequences (ISs), 4 intact and 1 questionable prophage regions, and 2 CRISPR elements suggesting possible genetic crosstalk, such as horizontal gene transfer among the E. coli population. The genome properties are presented in Table 3 . The distribution of genes into COGs functional categories is summarized in Table 4.

Table 3 Genome statistics

\begin{tabular}{lll}
\hline Attribute & Value & \% of Total \\
\hline Genome size (bp) & $4,782,107$ & 100.00 \\
DNA coding (bp) & $4,218,785$ & 88.22 \\
DNA G + C (bp) & $2,424,397$ & 50.70 \\
DNA scaffolds & 84 & \\
Total genes & 4562 & 100.00 \\
Protein coding genes & 4465 & 97.88 \\
RNA genes & 97 & 2.13 \\
Pseudo genes & 22 & 0.48 \\
Genes in internal clusters & 1171 & 25.67 \\
Genes with function prediction & 3831 & 83.98 \\
Genes assigned to COGs & 3814 & 83.60 \\
Genes with Pfam domains & 275 & 6.03 \\
Genes with signal peptides & 174 & 3.81 \\
Genes with transmembrane helices & 1080 & 23.67 \\
CRISPR repeats & 2 &
\end{tabular}

${ }^{a}$ The total is based on either the size of the genome in base pairs or the total number of proteins coding genes in the annotated genome

All the information has been obtained from Prokka annotation
Table 4 Number of genes associated with general COGs functional categories

\begin{tabular}{|c|c|c|c|}
\hline Code & Value & $\%$ age $^{a}$ & Description \\
\hline J & 250 & 6.55 & $\begin{array}{l}\text { Translation, ribosomal structure and } \\
\text { biogenesis }\end{array}$ \\
\hline A & 2 & 0.05 & RNA processing and modification \\
\hline K & 293 & 7.68 & Transcription \\
\hline L & 154 & 4.04 & Replication, recombination and repair \\
\hline B & 0 & 0.00 & Chromatin structure and dynamics \\
\hline D & 41 & 1.07 & $\begin{array}{l}\text { Cell cycle control, cell division, } \\
\text { chromosome partitioning }\end{array}$ \\
\hline V & 93 & 2.44 & Defense mechanisms \\
\hline T & 176 & 4.61 & Signal transduction mechanisms \\
\hline M & 271 & 7.11 & $\begin{array}{l}\text { Cell wall/membrane/envelope } \\
\text { biogenesis }\end{array}$ \\
\hline N & 156 & 4.09 & Cell motility \\
\hline$U$ & 60 & 1.57 & $\begin{array}{l}\text { Intracellular trafficking, secretion, } \\
\text { and vesicular transport }\end{array}$ \\
\hline O & 153 & 4.01 & $\begin{array}{l}\text { Post-translational modifications, } \\
\text { protein turnover, chaperones }\end{array}$ \\
\hline C & 282 & 7.39 & Energy production and conversion \\
\hline G & 381 & 9.99 & Carbohydrate transport and metabolism \\
\hline E & 335 & 8.78 & Amino acid transport and metabolism \\
\hline $\mathrm{F}$ & 101 & 2.65 & Nucleotide transport and metabolism \\
\hline H & 169 & 4.43 & Coenzyme transport and metabolism \\
\hline I & 119 & 3.12 & Lipid transport and metabolism \\
\hline$P$ & 190 & 4.98 & Inorganic ion transport and metabolism \\
\hline Q & 53 & 1.39 & $\begin{array}{l}\text { Secondary metabolites biosynthesis, } \\
\text { transport and catabolism }\end{array}$ \\
\hline $\mathrm{R}$ & 211 & 5.53 & General function prediction only \\
\hline$S$ & 238 & 6.24 & Function unknown \\
\hline- & 750 & 7.43 & Not in COGs \\
\hline
\end{tabular}

\section{Extended insights \\ Genome repertoire comparison}

It is admitted that bacterial genome sequences show significant diversity due to horizontal gene transfers, gene loss and other genomic rearrangements [1]. In this report, characteristics of whole genome datasets of a selection of E. coli strains were compared with those of E. coli BG1 (Table 5). Our main objective was to compare the genome of BG1 with that of bovine (K71 and W26) and human (SE15 and Nissle) commensal E. coli strains, but we also included a bovine pathogenic strain (VL2732) and a human EHEC pathogen (Sakai), as the bovine intestine is the main reservoir of EHEC [10]. A human uropathogenic strain $\left(\mathrm{NCTC} 9001^{\mathrm{T}}\right)$, which is also the E. coli type strain, was also included as reference. These strains were assigned to different phylogroups (Additional file 1: Table S1; Fig. 2). As expected, the 
Table 5 Characteristics of whole genome datasets of different E. coli strains

\begin{tabular}{|c|c|c|c|c|c|c|c|c|c|}
\hline Strain name & Phylo group & Origin $^{a}$ & Plasmid(s) & $\begin{array}{l}\text { Genome size (bp) } \\
\text { [chromosome }+ \text { plasmid(s)] }\end{array}$ & $\mathrm{G}+\mathrm{C}$ ratio (\%) & CDS (nb) & $\begin{array}{l}\text { Protein coding } \\
\text { regions }(n b)\end{array}$ & $\begin{array}{l}\text { rRNA operons } \\
(n b)^{b}\end{array}$ & $\begin{array}{l}\text { tRNA genes } \\
(n b)\end{array}$ \\
\hline BG1 & B1 & $\mathrm{BC}$ & 0 & $4,782,107$ & 50.7 & 4562 & 4465 & 8 & 86 \\
\hline K71 & B1 & $\mathrm{BC}$ & 0 & $5,115,070$ & 50.7 & 5178 & 4872 & 4 & 65 \\
\hline W26 & B1 & $\mathrm{BC}$ & 0 & $5,118,532$ & 50.6 & 4925 & 4852 & 4 & 66 \\
\hline Nissle 1917 & B2 & $\mathrm{Hc}$ & 0 & $5,441,200$ & 50.6 & 5417 & 4970 & 10 & 121 \\
\hline SE15 & B2 & $\mathrm{Hc}$ & 1 & $\begin{array}{l}4,839,683 \\
{[4,717,338+122,345]}\end{array}$ & 50.7 & 4763 & 4572 & 7 & 85 \\
\hline NCTC86 & A & $\mathrm{Hc}$ & 0 & $5,111,920$ & 50.6 & 5243 & 4934 & 7 & 87 \\
\hline VL2732 & A & Bp & 0 & $4,664,032$ & 50.6 & 4615 & 4363 & 4 & 71 \\
\hline Sakai & $\mathrm{E}$ & $\mathrm{Hp}$ & 2 & $\begin{array}{l}5,594,477 \\
{[5,498,450+92,721+3306]}\end{array}$ & 50.5 & 5447 & 5324 & 7 & 103 \\
\hline NCTC9001 $^{\top}$ & B2 & $\mathrm{Hp}$ & 0 & $5,038,133$ & 50.6 & 5154 & 4859 & 6 & 62 \\
\hline
\end{tabular}

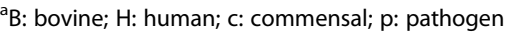

${ }^{\mathrm{b}}$ Minimal number of rRNA operons based on Prokka (BG1) or Genbank (K71, W26, VL2732, NCTC86, NCTC9001 ${ }^{\top}$ ) annotation or on rrnDB (version 5.1) information [69]

greatest difference in genome size was observed between BG1 and the EHEC strain Sakai (the genome size of BG1 is $812,370 \mathrm{bp}$ smaller than the Sakai genome [17.0\% of the BG1 genome]). This difference could be explained by the number of mobile genetic elements: the Sakai genome contains 18 prophage regions (at most 5 in the BG1 genome) and 80 insertion sequences (38 in the BG1 genome) [30]. About half of the Sakaispecific sequences are of bacteriophage origin and carry the genes involved in EHEC pathogenesis (bloody diarrhea, hemolytic uremic syndrome) [30]. More surprisingly, the chromosome length of the commensal E. coli Nissle 1917 is 659,093 bp larger than the BG1 genome (13.8\% of the BG1 genome). E. coli Nissle 1917 is a human commensal strain known to be a successful colonizer of the human gut and used as a probiotic for the treatment of various intestinal disorders [31]. It is well documented that the Nissle genome carries at least three genomic islands (GEIs) inserted at different tRNA sites (serX, $\arg W$ and pheV) probably acquired by horizontal gene transfer [32, 33]. These GEIs contained genes encoding proteins considered as fitness factors (microcins, iron uptake systems, proteases ...) contributing to survival of $E$. coli Nissle and successful colonization of the human body [32, 33]. These GEIs were found in non-pathogenic $E$. coli strains but were also frequently distributed among ExPEC strains [32]. Sequence comparison showed that the genes carried by Nissle 1917 GEIs (mch, mcm, iro, iuc, sat, iha, ybt) are absent in the BG1 genome, suggesting the absence of these GEIs in BG1.

In accordance with the differences in genome size, the highest number of tRNA genes, described as common sites for integration of foreign DNA elements (bacteriophages, genomic islands), were detected in the genome of E. coli strains Nissle and Sakai (121 and 103 tRNA genes, respectively while only 86 were identified in the BG1 draft genome (Table 5). The genome of the remaining strains carried 62 (in the type strain NCTC $9001^{\mathrm{T}}$ ) to 85 tRNA-encoding genes (Table 5). These numbers may be slightly different depending on the annotation pipeline used for the draft genome sequences.

\section{Virulence factors}

The genes encoding virulence factors in the E. coli BG1 genome were analyzed using blastn against the Virulence Factors Database genomic dataset [34]. A total of 164 genes encoding virulence factors were identified in BG1 (Additional file 2: Table S2), while 181 and 202 genes encoding virulence factors were found in the reference strains NCTC86 and NCTC9001 ${ }^{\mathrm{T}}$, respectively. In-depth analysis of the BG1 genome showed that most of these genes are involved in bacterial adherence to the host epithelium, iron acquisition systems (siderophores) and flagella synthesis. As expected, genes coding for toxins produced by pathogenic E. coli strains responsible for diarrhea or intestinal damage in mammals (Shiga-toxin, heat stable [ST] toxin, heat-labile [LT] toxin, heat-stable enterotoxin 1 [EAST1], cytotoxic necrotizing factor 1 [CNF1]) are absent in the BG1 genome. The E. coli BG1 genome also lacks the genes encoding $\alpha$-hemolysin and enterohemolysin which are involved in the virulence of pathogenic E. coli strains.

\section{Adherence systems}

A total of 49 genes coded for the synthesis of organelles involved in adherence of $E$. coli to host intestinal epithelium (Additional file 3: Table S3). Accordingly, the transmission electron micrograph of $E$. coli BG1 showed numerous fimbriae surrounding the bacteria (Fig. 1). Removal of partial genes and incomplete gene clusters 
Table 6 Adherence systems encoded by the E. coli BG1 genome

\begin{tabular}{|c|c|c|c|c|}
\hline Adherence system & Gene or genes cluster & Pathotype $^{a}$ & in vitro cell adherence ${ }^{b}$ & Receptor \\
\hline Curli fimbriae & $\operatorname{csg} D E F G, \operatorname{csg} B A$ & EHEC, ETEC, aEPEC, APEC & T84 & $\begin{array}{l}\text { Matrix, plasma } \\
\text { proteins }\end{array}$ \\
\hline EhaA autotransporter & ehaA & EHEC, EAEC, ETEC, AIEC, EPEC & $\begin{array}{l}\text { Primary bovine epithelial cells } \\
\text { (terminal rectum) }\end{array}$ & Unknown \\
\hline EhaB autotransporter & ehaB & EHEC, UPEC, ETEC, EIEC, EAEC & $N A^{c}$ & Collagen I, laminin \\
\hline EhaC autotransporter & ehaC (yfaL) & EHEC, UPEC & Unknown & Unknown \\
\hline ECP (E. coli Common Pilus) & ecpRABCDE & $\begin{array}{l}\text { ETEC, EHEC, NMEC, EAEC, } \\
\text { aEPEC, septicemia }\end{array}$ & HT29, Hep-2, HeLa, HTB-4 & Arabinosyl residues \\
\hline $\begin{array}{l}\text { ELF (E. coli Laminin-binding } \\
\text { Fimbriae) }\end{array}$ & ycbQRST & EHEC, aEPEC & HT29, Нep-2, MDBK & Laminin \\
\hline F9 Fimbriae & $z 2200-z 2206$ & $\begin{array}{l}\text { EHEC, UPEC, APEC, AIEC, } \\
\text { EAEC, EPEC }\end{array}$ & EBL & $\begin{array}{l}\text { Bovine fibronectin, } \\
\text { Galß1-3GlcNAc }\end{array}$ \\
\hline EaeH adhesin & eaeH & UPEC, EHEC, ETEC, NMEC & $\begin{array}{l}\text { UM-UC-3, Caco-2, CHO, } \\
\text { HeLa, Vero }\end{array}$ & Unknown \\
\hline HCP (Hemorrhagic Coli Pilus) & hсpABC (ppdD-hofBC) & ETEC, EHEC, aEPEC, APEC & $\begin{array}{l}\text { T84, Caco-2, HeLa, Hep-2, } \\
\text { MDBK, cow colon explants }\end{array}$ & Laminin, fibronectin \\
\hline Stg fimbriae & $\operatorname{stg} A B C D$ & APEC, UPEC & UM-UC-3, INT 407 & Unknown \\
\hline T1P (Type I pili) & fimBE, fimAlCDFGH & UPEC, aEPEC, EAEC, APEC, STEC & $\begin{array}{l}\text { HeLa, REC, colonic and ileal } \\
\text { enterocytes }\end{array}$ & Mannose \\
\hline UpaG autotransporter & upaG & UPEC & T24 & Fibronectin, laminin \\
\hline
\end{tabular}

revealed that BG1 possessed the genetic information required to encode 12 potentially functional full adherence systems (Table 6). All these systems are known to be produced by pathogenic $E$. coli and to adhere in vitro to different cells lines (Table 6) (for reviews see [35-37]). These adherence systems reflect the ability of commensal $E$. coli to colonize distinct niches during its transit through the different compartments of the bovine gastro-intestinal tract. It is also of interest to note that some of these adherence systems possess characteristics corresponding to physiological conditions encountered in the bovine gastro-intestinal tract: i) eaeH expression is induced at $39{ }^{\circ} \mathrm{C}$, the internal bovine temperature, but not at $37^{\circ} \mathrm{C}$ [38] ii) the pili HCP is involved in adherence of E. coli to bovine gut explants [39] and iii) the F9 fimbriae are essential for in vivo colonization of calves [40]. Furthermore, the stg and F9 gene clusters are strongly associated with $E$. coli belonging to phylogenetic group B1 [41, 42]. To broaden these results, in silico analysis of adherence systems carried by additional $E$. coli strains (human and bovine commensal and pathogenic isolates) (Additional file 1: Table S1; Additional file 4: Figure S1) was also performed. A hierarchical clustering based on the presence/absence of 78 distinct adherence systems encoding genes was built using $\mathrm{R}$ (version 3.3.1) [43]. As shown in Additional file 4: Figure S1, bovine and human $E$. coli strains were not separately distributed (the closest relative strains to BG1 were the human E. coli strains S11 and IAI1 [Additional file 4: Figure S1]) suggesting that the adherence systems are associated with the adaptation of $E$. coli to a specific habitat (i.e. the digestive tract) rather than host specificity. As expected, the uropathogenic strain $\mathrm{NCTC} 9001^{\mathrm{T}}$ possesses the pap ACDEGHIK genes which are specific to UPEC strains [44].

Some of these adherence systems possess redundant properties: EhaB, ELF, HCP and UpaG are known to bind to laminin and curli, EhaA, EhaB, EhaC, ECP, F9, EaeH, HCP and UpaG are involved in biofilm formation (Table 6). This suggested an important role of both laminin binding and biofilm formation in survival and/or multiplication of commensal E. coli. Laminin is an extracellular matrix commonly present in the mammalian intestine which act as an interlinking molecule in connective tissues that promote bacterial adhesion and colonization to the host tissues [45]. Moreover, commensal E. coli strains can reside in mixed biofilms in the mucus layer covering the mouse intestine $[4,46]$. Because the survival of $E$. coli depends on anaerobes that degrade polysaccharides included in the mucus layer, it has been hypothesized that the anaerobes in the mixed biofilms provide $E$. 
coli with monosaccharide locally rather than from a mixed pool available to all species $[4,46]$. Therefore, the mixed biofilm formation can results in a more efficient carbon source for commensal $E$. coli strains in the mammalian gut $[4,46]$.

As discussed above, the adhesion systems encoded by the BG1 genome were associated with E. coli strains mostly isolated from clinical cases (Table 6). However, it is important to note that the BG1 genome did not carry the genes encoding the F17, F5 and F41 fimbriae and the afimbrial adhesin CS31A mainly associated with bovine pathogenic E. coli strains involved in diarrhea [47]. For example, a recent epidemiological study showed that the F5/F41 fimbriae were prevalent among bovine diarrheagenic E. coli isolated in France [48]. The genes encoding F17, F5 and F41 are not detected in the genome of the human and bovine E. coli strains included in this study suggesting that these adherence systems are specific to bovine intestinal pathogenic E. coli.

\section{Flagella synthesis}

A total of 47 genes encoding proteins required for flagella synthesis were present in the BG1 genome. Accordingly, the transmission electron micrograph of E. coli BG1 showed peritrichous flagella attached to the bacterial cell surface and clearly distinct from fimbriae (Fig. 1). Flagella are mainly locomotive organelles allowing bacterial movements. However, it is well documented that the flagella (also known as $\mathrm{H}$ antigen) of some pathogenic E. coli mediate the adhesion to or invasion of epithelial cells (NMEC, aEPEC, ETEC, EAEC, EHEC, APEC) and contribute to biofilm formation (UPEC, ETEC) (for a review see Zhou et al. [49]). In particular, flagella of aEPEC, ETEC and EHEC strains specifically recognized a receptor located at the microvillus tips of human enterocytes [50]. Interestingly, E. coli BG1 possesses the genetic information required to encode the flagella $\mathrm{H} 21$, a $\mathrm{H}$ antigen type reported to be involved in the invasion of EHEC O113:H21 into HCT-8 colonic epithelial cells [49]. Also, it should be noted that STEC strains with serotype O159:H21 have been isolated from bovine as well as porcine feces [51, 52].

\section{Iron acquisition systems}

Complete genetic information required for enterobactin synthesis (entABCDEFS) and ferric-enterobactin uptake (fepABCDEFG) was present in the genome of E. coli BG1 (Additional file 2: Table S2). Siderophores, including enterobactin, are mechanisms secreted by $E$. coli to scavenge iron in order to survive and multiply in hosts or external environments. Siderophores are usually described as crucial for the proliferation of pathogenic $E$. coli in the host and have been classified as virulence factors. However, enterobactin is frequently produced by commensal $E$. coli isolated from healthy mammals (human and animal isolates) [53]. ent and fep genes were also found in the genome of the reference strain NCTC86 (data not shown). Accordingly, Pi et al. have demonstrated that enterobactin plays a fundamental role in the colonization of healthy mouse gastro-intestinal tract by non-pathogenic E. coli [54].

\section{Ethanolamine utilization}

In a previous study, we demonstrated that ethanolamine present in the bovine gut is used by EHEC as a nitrogen source [11]. Furthermore, ethanolamine promotes expression of fimbrial genes and influenced EHEC adherence to epithelial cells [55]. Interestingly, E. coli BG1 is unable to degrade ethanolamine present in the bovine intestine, while the EHEC reference strain EDL933 gains a growth competitive advantage by assimilating ethanolamine in bovine intestinal content [11]. Therefore, we performed in-depth analysis of the genes involved in ethanolamine utilization in order to understand the inability of the commensal strain BG1 to use ethanolamine as a nitrogen source.

The degradation and assimilation of ethanolamine by EHEC EDL933 requires exogenous adenosylcobalamin (Ado-Cbl) and are encoded by 17 genes included in the eut operon [11]. In this study, we used blastn and Seaview (version 4.6.1) [56] to compare the eut genes of $E$. coli BG1 with those of EHEC EDL933. Sequence alignment showed 317 SNPs between the two eut operons (97.82\% identity) (Additional file 5: Table S4). In addition, no premature stop codon was detected and only 34 amino acid changes due to non-synonymous SNPs were identified among the 17 predicted polypeptides encoded by the eut operon of BG1 (Additional file 5: Table S4). Furthermore, the presence of a 72 bp insertion was also identified in the eut $T$ gene coding for cobalamin adenosyltransferase in the BG1 genome compared with the EDL933 genome (Additional file 6: Figure S2). It is important to note that ethanolamine ammonia-lyase, the key enzyme in ethanolamine degradation, required the Ado-Cbl cofactor produced by EutT to be active. The $72 \mathrm{bp}$ insertion sequence at position 395 resulted in a modified translated polypeptide with 24 additional amino acids at position 132. The possible EutT conformation illustrated in Fig. 3 was predicted using Phyre (version 2.0) [57] and showed that 18 of the 24 amino acids encoded by the 72 bp sequence were predicted to form an additional alpha helix in the BG1 EutT protein.

In summary, in view of the 34 amino acid changes due to non-synonymous SNPs among the 17 predicted polypeptides encoded by the eut operon and the prediction 


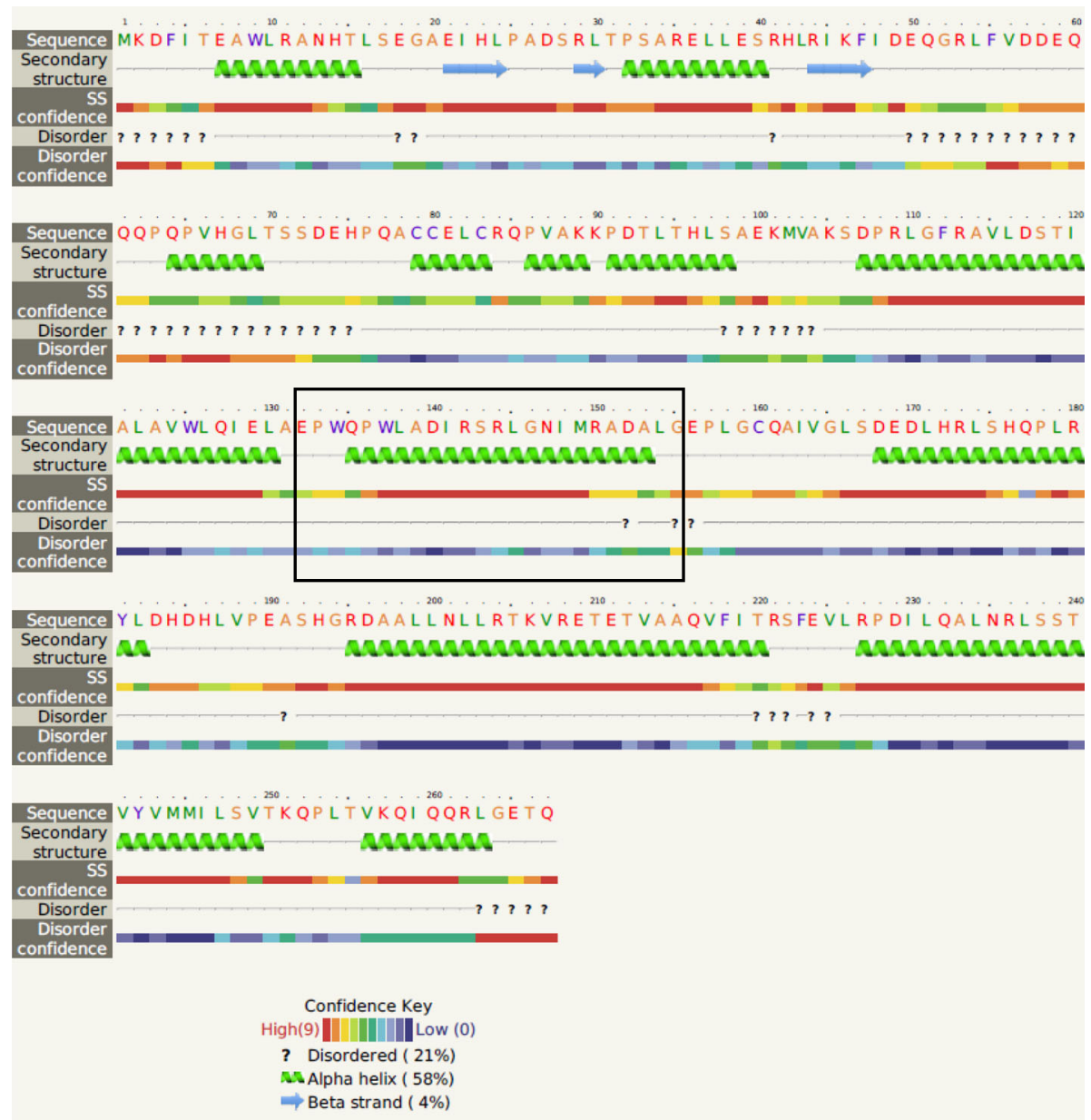

Fig. 3 Predicted secondary structure modeling of the EutT protein of E. coli BG1 obtained with Phyre version 2.0 [57]

of an additional alpha helix in BG1 EutT cobalamin adenosyltransferase, we suspected a reduced or abolished ethanolamine ammonialyase activity, which could explain the inability of BG1 to assimilate ethanolamine in the bovine digestive tract.

\section{Conclusion}

The comparison of whole genomes provides information on gene content and organization, and gives an overview of how organisms are related. The draft genome sequence of $E$. coli BG1 isolated from the bovine intestine is now available and can provide valuable information at the genomic scale to explore the genetic and functional features adapted to the bovine gut. The genome of $E$. coli BG1 can be used as a reference for subsequent evolution and comparative studies (some examples of genome comparative analysis have already been described in this report).

As expected, the BG1 genome does not carry the genetic information encoding toxins responsible for intestinal damage. More surprisingly, the E. coli BG1 strain possesses the genetic information required to encode systems classified as "virulence factors" and produced by pathogenic E. coli. This could suggest that genes encoding virulence factors are "in transit" from commensal species that act as genetic depositories with the ability to transmit DNA fragments to pathogenic $E$. coli strains. However, both pathogenic and nonpathogenic E. coli strains are able to colonize the gut and seem to use similar factors to adhere to the host epithelial cells. Therefore, it is questionable whether the ability of intestinal $E$. coli to colonize the host gut (resistance to the intestinal flux), excrete siderophores (iron uptake from the surrounding environment) and produce flagella (capacity to move toward nutrient-rich environments) can be considered as "virulence factors". The terms "virulence", "fitness" and "colonization" factors appear to overlap for $E$. coli species. In fact, factors contributing to $E$. coli survival in a given environment should be considered as fitness and adaptation factors 
enabling successful colonization of the host rather than strict markers of pathogenesis. In contrast, the factors responsible for disease establishment or intestinal damages during infection (e.g. aqueous or hemorrhagic diarrhea), such as toxins or the type III secretion system, appear to be true virulence factors.

\section{Additional files}

Additional file 1: Table S1. E. coli strains included in this study (XLSX $13 \mathrm{~kb}$ ) Additional file 2: Table S2. Genes encoding virulence factors in the $E$. coli BG1 genome (XLSX $31 \mathrm{~kb}$ )

Additional file 3: Table S3. Genes encoding adherence systems in E. coli BG1 genome (XLSX $11 \mathrm{~kb}$ )

Additional file 4: Figure S1. Hierarchical clustering of $E$. coli strains according to adherence systems encoding genes. The dendrogram and associated heatmap are generated on the basis of gene presence/absence considering 78 genes involved in adherence, using binary distance and complete clustering method, $R$ version 3.3.1. [43]. Blue color indicates gene presence, red gene absence. The origin of each strain is identified with $B$ (Bovine) or $\mathrm{H}$ (Human). The color of the strain name corresponds to its phylogroup as in Fig. 2. (DOCX 67 kb)

Additional file 5: Table S4. Genes encoding the transport and assimilation of ethanolamine in E. coli BG1 genome. (XLSX $12 \mathrm{~kb}$ )

Additional file 6: Figure S2. Nucleotide sequence alignment of the eutT gene. The sequences of the eutT gene and the translated EutT polypeptide were aligned respectively from E. coli strains BG1 and EDL933 using Seaview version 4.6.1 [56]. (DOCX 15 kb)

\section{Abbreviations}

AIEC: Adherent-invasive E. coli; APEC: Avian pathogenic E. coli; EAggEC: Enteroaggregative E. coli; EHEC: Enterohemorrhagic E. colli; EPEC: Enteropathogenic E. coli; ETEC: Enterotoxigenic E. coli; EXPEC: Extraintestinal pathogenic E. coli; NMEC: Neonatal meningitis E. coli; STEC: Shiga-producing E. coli; UPEC: Uropathogenic E. coli

\section{Acknowledgements}

The authors thank Frédérique Chaucheyras-Durand for critical reading of the manuscript, Alexandra Durand and Marine Bertoni for excellent technical assistance, Brigitte Gaillard-Martinie for the transmission electron microscopy and Olivier Bouchez for genome sequencing. The genome sequencing was performed at the GeT core facility, Toulouse, France (http://get.genotoul.fr), and was supported by France Génomique National infrastructure, funded as part of the "Investissement d'avenir" program managed by the Agence Nationale pour la Recherche (contract ANR-10-INBS-09). We are also grateful to the Genotoul bioinformatics platform Toulouse Midi-Pyrenées (Genotoul Bioinfo) for providing computing and storage resources.

\section{Authors' contributions}

$E F$ and YB designed and coordinated the study; PA and CK performed the bioinformatic analysis; CK performed the genome assembly and annotation; AS performed the laboratory experiments; EF, YB, PA, AS and CK wrote the manuscript. All the authors read and approved the final manuscript.

\section{Competing interests}

The authors declare that they have no competing interests.

\section{Publisher's Note}

Springer Nature remains neutral with regard to jurisdictional claims in published maps and institutional affiliations.

\section{Author details}

'Université Clermont Auvergne, INRA, MEDIS, F-63000 Clermont-Ferrand, France. ${ }^{2}$ Plateforme Bioinformatique Toulouse, Midi-Pyrénées UBIA, INRA, Auzeville Castanet-Tolosan, France.
Received: 7 March 2017 Accepted: 21 September 2017

Published online: 10 October 2017

\section{References}

1. Welch RA. The genus Escherichia. In: Dworkin M, Falkow S, Rosenberg E, Schleifer K-H, Stackebrandt E, editors. The Prokaryotes, vol. 6. Third ed. Berlin: Springer; 2006. p. 60-71.

2. Blount ZD. The unexhausted potential of E. coli. elife. 2015;4:e05826.

3. Jones SA, Gibson T, Maltby RC, Chowdhury FZ, Stewart V, Cohen PS, Conway T. Anaerobic respiration of Escherichia coli in the mouse intestine. Infect Immun. 2011:79:4218-26.

4. Conway T, Cohen PS. Commensal and pathogenic Escherichia coli metabolism in the gut. Microbiol Spectr. 2015; doi:10.1128/microbiolspec. MBP-0006-2014.

5. Kaper JB, Nataro JP, Mobley HL. Pathogenic Escherichia coli. Nat Rev Microbiol. 2004;2:123-40.

6. Karmali MA, Gannon V, Sargeant JM. Verocytotoxin-producing Escherichia coli (VTEC). Vet Microbiol. 2010;140:360-70.

7. Oshima K, Toh H, Ogura Y, Sasamoto H, Morita H, Park SH, Ooka T, lyoda S, Taylor TD, Hayashi T, et al. Complete genome sequence and comparative analysis of the wild-type commensal Escherichia coli strain SE11 isolated from a healthy adult. DNA Res. 2008;15:375-86.

8. Rasko DA, Rosovitz MJ, Myers GS, Mongodin EF, Fricke WF, Gajer P, Crabtree J, Sebaihia M, Thomson NR, Chaudhuri R, et al. The pangenome structure of Escherichia coli: comparative genomic analysis of E. coli commensal and pathogenic isolates. J Bacteriol. 2008;190:6881-93.

9. Toh H, Oshima K, Toyoda A, Ogura Y, Ooka T, Sasamoto H, Park SH, lyoda S, Kurokawa K, Morita $\mathrm{H}$, et al. Complete genome sequence of the wild-type commensal Escherichia coli strain SE15, belonging to phylogenetic group B2. J Bacteriol. 2010;192:1165-6.

10. Bertin Y, Chaucheyras-Durand F, Robbe-Masselot C, Durand A, de la Foye A, Harel J, Cohen PS, Conway T, Forano E, Martin C. Carbohydrate utilization by enterohaemorrhagic Escherichia coli O157:H7 in bovine intestinal content. Environ Microbiol. 2013;15:610-22.

11. Bertin Y, Girardeau JP, Chaucheyras-Durand F, Lyan B, Pujos-Guillot E, Harel J, Martin C. Enterohaemorrhagic Escherichia coli gains a competitive advantage by using ethanolamine as a nitrogen source in the bovine intestinal content. Environ Microbiol. 2011;13:365-77.

12. Joensen KG, Tetzschner AM, Iguchi A, Aarestrup FM, Scheutz F. Rapid and easy in silico serotyping of Escherichia coli isolates by use of whole-genome sequencing data. J Clin Microbiol. 2015;53:2410-26.

13. Zankari E, Hasman $H$, Cosentino S, Vestergaard M, Rasmussen S, Lund $O$, Aarestrup FM, Larsen MV. Identification of acquired antimicrobial resistance genes. J Antimicrob Chemother. 2012;67:2640-4.

14. Clermont O, Christenson JK, Denamur E, Gordon DM. The Clermont Escherichia coli phylo-typing method revisited: improvement of specificity and detection of new phylo-groups. Environ Microbiol Rep. 2013;5:58-65.

15. Rice P, Longden I, Bleasby A. EMBOSS: the European Molecular Biology Open Software Suite. Trends Genet. 2000;16:276-7.

16. Askari Badouei M, Jajarmi M, Mirsalehian A. Virulence profiling and genetic relatedness of Shiga toxin-producing Escherichia coli isolated from humans and ruminants. Comp Immunol Microbiol Infect Dis. 2015;38:15-20.

17. Bok E, Mazurek J, Stosik M, Wojciech M, Baldy-Chudzik K. Prevalence of virulence determinants and antimicrobial resistance among commensal Escherichia coli derived from dairy and beef cattle. Int J Environ Res Public Health. 2015;12:970-85.

18. Kaas RS, Leekitcharoenphon P, Aarestrup FM, Lund O. Solving the problem of comparing whole bacterial genomes across different sequencing platforms. PLoS One. 2014;9:e104984.

19. Mariette J, Escudie F, Allias N, Salin G, Noirot C, Thomas S, Klopp C. NG6: Integrated next generation sequencing storage and processing environment. BMC Genomics. 2012;13:462

20. Andrews, S. FastQC: a quality control tool for high throughput sequence data. 2010. http://www.bioinformatics.babraham.ac.uk/projects/fastqc/. Accessed 10 Oct 2016

21. Bankevich A, Nurk S, Antipov D, Gurevich AA, Dvorkin M, Kulikov AS, Lesin VM, Nikolenko SI, Pham S, Prjibelski AD, et al. SPAdes: a new genome assembly algorithm and its applications to single-cell sequencing. J Comput Biol. 2012;19:455-77. 
22. Seemann T. Prokka: rapid prokaryotic genome annotation. Bioinformatics. 2014;30:2068-9.

23. Geer LY, Marchler-Bauer A, Geer RC, Han L, He J, He S, Liu C, Shi W, Bryant SH. The NCBI BioSystems database. Nucleic Acids Res. 2010;38:D492-6.

24. Krogh A, Larsson B, von Heijne G, Sonnhammer EL. Predicting transmembrane protein topology with a hidden Markov model: application to complete genomes. J Mol Biol. 2001;305:567-80.

25. Petersen TN, Brunak S, von Heijne G, Nielsen H. SignalP 4.0: discriminating signal peptides from transmembrane regions. Nat Methods. 2011:8:785-6.

26. Grissa I, Vergnaud G, Pourcel C. CRISPRFinder: a web tool to identify clustered regularly interspaced short palindromic repeats. Nucleic Acids Res. 2007;35:W52-7.

27. Varani AM, Siguier P, Gourbeyre E, Charneau V, Chandler M. ISsaga is an ensemble of web-based methods for high throughput identification and semi-automatic annotation of insertion sequences in prokaryotic genomes. Genome Biol. 2011;12:R30

28. Arndt D, Grant JR, Marcu A, Sajed T, Pon A, Liang Y, Wishart DS. PHASTER: a better, faster version of the PHAST phage search tool. Nucleic Acids Res. 2016;44:W16-21.

29. Carattoli A, Zankari E, Garcia-Fernandez A, Voldby Larsen M, Lund O, Villa L, Moller Aarestrup F, Hasman H. In silico detection and typing of plasmids using PlasmidFinder and plasmid multilocus sequence typing. Antimicrob Agents Chemother. 2014;58:3895-903.

30. Hayashi T, Makino K, Ohnishi M, Kurokawa K, Ishii K, Yokoyama K, Han CG, Ohtsubo E, Nakayama K, Murata T, et al. Complete genome sequence of enterohemorrhagic Escherichia coli 0157:H7 and genomic comparison with a laboratory strain K-12. DNA Res. 2001;8:11-22.

31. Lodinova-Zadnikova R, Sonnenborn U. Effect of preventive administration of a nonpathogenic Escherichia coli strain on the colonization of the intestine with microbial pathogens in newborn infants. Biol Neonate. 1997;71:224-32.

32. Grozdanov L, Raasch C, Schulze J, Sonnenborn U, Gottschalk G, Hacker J, Dobrindt $U$. Analysis of the genome structure of the nonpathogenic probiotic Escherichia coli strain Nissle 1917. J Bacteriol. 2004;186:5432-41.

33. Sun J, Gunzer F, Westendorf AM, Buer J, Scharfe M, Jarek M, Gossling F, Blocker $\mathrm{H}$, Zeng AP. Genomic peculiarity of coding sequences and metabolic potential of probiotic Escherichia coli strain Nissle 1917 inferred from raw genome data. J Biotechnol. 2005;117:147-61.

34. Chen L, Yang J, Yu J, Yao Z, Sun L, Shen Y, Jin Q. VFDB: a reference database for bacterial virulence factors. Nucleic Acids Res. 2005;33:D325-8.

35. Antao EM, Wieler LH, Ewers C. Adhesive threads of extraintestinal pathogenic Escherichia coli. Gut Pathog. 2009;1:22.

36. Croxen MA, Law RJ, Scholz R, Keeney KM, Wlodarska M, Finlay BB. Recent advances in understanding enteric pathogenic Escherichia coli. Clin Microbiol Rev. 2013;26:822-80.

37. McWilliams BD, Torres AG. Enterohemorrhagic Escherichia coli adhesins. Microbiol Spectrum. 2014; doi: 10.1128/microbiolspec.EHEC-0003-2013.

38. Easton DM, Allsopp LP, Phan MD, Moriel DG, Goh GK, Beatson SA, Mahony TJ, Cobbold RN, Schembri MA. The intimin-like protein FdeC is regulated by $\mathrm{H}-\mathrm{NS}$ and temperature in enterohemorrhagic Escherichia coli. Appl Environ Microbiol. 2014;80:7337-47.

39. Xicohtencatl-Cortes J, Monteiro-Neto V, Ledesma MA, Jordan DM, Francetic O, Kaper JB, Puente JL, Giron JA. Intestinal adherence associated with type IV pili of enterohemorrhagic Escherichia coli 0157:H7. J Clin Invest. 2007;117:3519-29.

40. Dziva F, van Diemen PM, Stevens MP, Smith AJ, Wallis TS. Identification of Escherichia coli $\mathrm{O} 157$ : H7 genes influencing colonization of the bovine gastrointestinal tract using signature-tagged mutagenesis. Microbiology. 2004;150:3631-45.

41. Lymberopoulos MH, Houle S, Daigle F, Leveille S, Bree A, Moulin-Schouleur M, Johnson JR, Dozois CM. Characterization of Stg fimbriae from an avian pathogenic Escherichia coli O78:K80 strain and assessment of their contribution to colonization of the chicken respiratory tract. J Bacteriol. 2006;188:6449-59.

42. Wurpel DJ, Totsika M, Allsopp LP, Hartley-Tassell LE, Day CJ, Peters KM, Sarkar S, Ulett GC, Yang J, Tiralongo J, et al. F9 fimbriae of uropathogenic Escherichia coli are expressed at low temperature and recognise Galbeta13GlcNAc-containing glycans. PLoS One. 2014;9:e93177.

43. Team RC. R: A language and environment for statistical computing. Vienna, Austria: The R Project for Statistical Computing; 2016

44. Arthur M, Campanelli C, Arbeit RD, Kim C, Steinbach S, Johnson CE, Rubin RH, Goldstein R. Structure and copy number of gene clusters related to the pap Padhesin operon of uropathogenic Escherichia coli. Infect Immun. 1989;57:314-21.
45. Simon-Assmann P, Spenle C, Lefebvre O, Kedinger M. The role of the basement membrane as a modulator of intestinal epithelial-mesenchymal interactions. Prog Mol Biol Transl Sci. 2010;96:175-206.

46. Leatham-Jensen MP, Frimodt-Moller J, Adediran J, Mokszycki ME, Banner ME, Caughron JE, Krogfelt KA, Conway T, Cohen PS. The streptomycin-treated mouse intestine selects Escherichia coli envZ missense mutants that interact with dense and diverse intestinal microbiota. Infect Immun. 2012;80:1716-27.

47. Nagy B, Fekete PZ. Enterotoxigenic Escherichia coli in veterinary medicine. Int J Med Microbiol. 2005;295:443-54.

48. Valat C, Forest K, Auvray F, Metayer V, Meheut T, Polizzi C, Gay E, Haenni M, Oswald E, Madec JY. Assessment of adhesins as an indicator of pathovarassociated virulence factors in bovine Escherichia coli. Appl Environ Microbiol. 2014:80:7230-4.

49. Zhou M, Yang Y, Chen P, Hu H, Hardwidge PR, Zhu G. More than a locomotive organelle: flagella in Escherichia coli. Appl Microbiol Biotechnol. 2015;99:8883-90.

50. Sampaio SC, Luiz WB, Vieira MA, Ferreira RC, Garcia BG, Sinigaglia-Coimbra R, Sampaio JL, Ferreira LC, Gomes TA. Flagellar cap protein FliD mediates adherence of atypical enteropathogenic Escherichia coli to enterocyte microvilli. Infect Immun. 2016;84:1112-22.

51. Baranzoni GM, Fratamico PM, Gangiredla J, Patel I, Bagi LK, Delannoy S, Fach P, Boccia F, Anastasio A, Pepe T. Characterization of shiga toxin subtypes and virulence genes in porcine shiga toxin-producing Escherichia coli. Front Microbiol. 2016;7:574.

52. Pigatto CP, Schocken-Iturrino RP, Souza EM, Pedrosa FO, Comarella L, Irino K, Kato MA, Farah SM, Warth JF, Fadel-Picheth CM. Virulence properties and antimicrobial susceptibility of Shiga toxin-producing Escherichia coli strains isolated from healthy cattle from Parana State. Brazil Can J Microbiol. 2008;54:588-93.

53. Searle LJ, Meric G, Porcelli I, Sheppard SK, Lucchini S. Variation in siderophore biosynthetic gene distribution and production across environmental and faecal populations of Escherichia coli. PLoS One. 2015;10:e0117906.

54. Pi H, Jones SA, Mercer LE, Meador JP, Caughron JE, Jordan L, Newton SM, Conway T, Klebba PE. Role of catecholate siderophores in gram-negative bacterial colonization of the mouse gut. PLoS One. 2012;7:e50020.

55. Garsin DA. Ethanolamine utilization in bacterial pathogens: roles and regulation. Nat Rev Microbiol. 2010;8:290-5.

56. Gouy M, Guindon S, Gascuel O. SeaView version 4: A multiplatform graphical user interface for sequence alignment and phylogenetic tree building. Mol Biol Evol. 2010;27:221-4.

57. Kelley LA, Mezulis S, Yates CM, Wass MN, Sternberg MJ. The Phyre2 web portal for protein modeling, prediction and analysis. Nat Protoc. 2015;10:845-58.

58. Field D, Garrity G, Gray T, Morrison N, Selengut J, Sterk P, Tatusova T, Thomson N, Allen MJ, Angiuoli SV, et al. The minimum information about a genome sequence (MIGS) specification. Nat Biotechnol. 2008;26:541-7.

59. Woese CR, Kandler O, Wheelis ML. Towards a natural system of organisms: proposal for the domains Archaea, Bacteria, and Eucarya. Proc Natl Acad Sci U S A. 1990;87:4576-9.

60. Garrity GM, Bell JA, Lilburn T. Phylum XIV. Proteobacteria phyl. nov. In: Garrity GM, Brenner DJ, Krieg NR, Staley JR, editors. Bergey's Manual of Systematic Bacteriology. Second edition, Volume 2, Part B. New York: Springer; 2005: p. 1.

61. Garrity GM, Bell JA, Lilburn T. Class III. Gammaproteobacteria class. nov. In: Garrity GM, Brenner DJ, Krieg NR, Staley JR, editors. Bergey's Manual of Systematic Bacteriology. Second edition, Volume 2, Part B. New York: Springer; 2005. p. 1.

62. Euzeby J. Validation list no. 106. Validation of publication of new names and new combinations previously effectively published outside the IJSEM. Int J Syst Evol Microbiol. 2005;55:2235-8.

63. Garrity GM, Holt JG. Taxonomic outline of the archaea and bacteria. In: Garrity GM, Boone DR, Castenholz RW, editors. Bergey's Manual of Systematic Bacteriology, vol. 1. Second ed. New York: Springer; 2001. p. 155-66.

64. Hill LR, Skerman VBD, Sneath PHA. Corrigenda to the approved lists of bacterial names: edited for the international committee on systematic bacteriology. Int J Syst Bacteriol. 1984;34:508-11.

65. Rahn O. New principles for the classification of bacteria. Zentralblatt für Backteriologie, Parasitenkunde, Infektionskrankheiten und Hygiene. 1937;96:273-86.

66. Skerman VBD, McGowan V, Sneath PHA. Approved lists of bacterial names. Int J Syst Bacteriol. 1980:225-420.

67. Castellani A, Chalmers AJ. Genus Escherichia Castellani and Chalmers, 1918. Wood W. And Co. Manual of Tropical Medicine. Third edition. New York; William Wood and Company; 1919. p.941-3. 
68. Ashburner M, Ball CA, Blake JA, Botstein D, Butler H, Cherry JM, Davis AP, Dolinski K, Dwight SS, Eppig JT, et al. Gene ontology: tool for the unification of biology. The Gene Ontology Consortium. Nat Genet. 2000;25:25-9.

69. Stoddard SF, Smith BJ, Hein R, Roller BR, Schmidt TM. rrnDB: improved tools for interpreting rRNA gene abundance in bacteria and archaea and a new foundation for future development. Nucleic Acids Res. 2015;43:D593-8.

Submit your next manuscript to BioMed Central and we will help you at every step:

- We accept pre-submission inquiries

- Our selector tool helps you to find the most relevant journal

- We provide round the clock customer support

- Convenient online submission

- Thorough peer review

- Inclusion in PubMed and all major indexing services

- Maximum visibility for your research

Submit your manuscript at www.biomedcentral.com/submit 